\title{
Political communication on Facebook: A case study of the European Parliament profile page for the elections $2009^{1}$
}

\author{
Lucia Vesnić-Alujević ${ }^{2}$
}

Ghent University, Ghent, Belgium

UDC 324(4-672EU)'2009' : 32.019.51:004.773.6/.7

Summary: This study examines the use of Facebook in political communication during the 2009 European Parliament elections campaign. Its goal is to explore the possibilities of the European Parliament communication strategy on Facebook as well as the interaction and participation of its online audiences. The analysis has discovered new concepts significant for the field of online political advertising, the specific campaign construction with its key themes and the particular form of interaction. The original contribution of this paper is seen in its efforts to reveal the campaign of the European Parliament on Facebook, which was not previously studied.

Key words: Facebook, participation, elections, campaigns, discourse analysis, European Parliament

\section{Introduction}

One major difference between the Internet and other media since the emergence of web 2.0 is the possibility of a direct feedback. A direct reciprocal connection in message exchanges is possible to an indefinite number of consumers, without eye-to-eye contact (Maarek \& Wolfsfeld, 2003). Therefore, it is worth researching whether or not citizens are interested in using these opportunities, engaging in the direct interaction, and how interested they are. Furthermore, can we speak only about the interaction or also about participation between citizens and political actors.

\footnotetext{
1 This text is part of the PhD thesis "The Role of Internet in Political Communication: A case study of the 2009 European Parliament elections” defended at Ghent University in November 2011.

2 lucy.vessal@gmail.com.
} 
Young adults are often seen as a target group of online political communication as they were less engaged in politics than other citizens (Baumgartner \& Morris, 2010). According to Delli Carpini (2000), in the classical political communication, the political institutions and actors disconnected young adults from public life by paying no attention to them and to the topics that matter to them, thus not supplying them with the opportunities to participate. The author wondered back in 2000 whether the new media will offer new opportunities for civil engagement, as in 1999 the Internet was already seen "as the most useful source of such [political and issue] information" among young adults between 18 and 35 years old (Delli Carpini, 2000: 346). Lusoli suggests that the Internet contributes to the "liberation" of the younger generation as it "unlocks participation from traditional authority structures and information gatekeepers" (Lusoli, 2005: 155).

According to the official statistics, Facebook has more than 500 million active users, which means that it is used by every fourteenth person on Earth (Facebook, 2010). Therefore, based on the number of consumers, it can be considered an appropriate medium for political advertising, both for individuals and organizations. Facebook gives opportunities to political actors to be closer to citizens. But, the successfulness of a political campaign on a social network site (SNS) such as Facebook is difficult to evaluate. We can think about what is more important: the number of fans of a certain SNS profile or the number of fans who are active participants in the discussion. These two issues could be explained through the classic concept of the "audience reach" in regards to the number of fans and the "quality of reach" when it comes to active participants. But then, we also need to make a distinction between a "like" ${ }^{3}$ and a real comment, in regards to the notion of participation. Also, we can raise a question about which exact number of fans is relevant for a profile $e^{4}$ on Facebook, especially if it is a profile of a political institution, which is not common on Facebook (e.g. the French National Assembly has 27 fans, the UK Parliament has 3,109 fans, the Italian Parliament has 12 fans etc.).

Although the EP campaign is not as interesting as the campaign of individual parties competing for the seats in the parliament, its importance is un-

\footnotetext{
A "like" is a Facebook option that provides a feedback on someone's post. It is considered to be an acknowledgement of a post "in a positive way without needing to add actual commentary" (Webopedia, 2010).

4 A "profile page" is a webpage created on Facebook by a user, after his subscription to the website and can include different features like name, picture, address, date of birth, interests, etc. The formation of a "profile page" is a prerequisite for the communication with other users on Facebook, thus it is essential for being a part of the network.
} 
deniable because its goal was, apart from engaging the EU citizens, to stop the further decrease of turnout.

This paper shows the potentials in Europe for the use of Facebook in political and institutional communication and how the participants, EU citizens, reacted on it. The use of the Internet and web 2.0 is important for the field of political communication and political marketing because it represents, as a new medium which is potentially useful for mobilization of audiences, a new way of political advertising and promotion. It shows the importance to study new media, different formats and other platforms, but at the same time it stresses the theoretical and methodological difficulties in studying online data. In addition, through the presentation of the empirical part of web 2.0, it demonstrates possibilities for new ways of communication not only for citizens, but also political actors and institutions.

\section{Interaction and participation}

Three major notions when speaking about the web 2.0 are certainly access, interaction and participation. While it is easy to make a distinction between access and the other two terms, the distinction between interaction and participation is rather blurred and sometimes confusing. In his visual essay "Rescuing Participation", Carpentier (2007) makes a distinction between these two terms using Pateman's definition of partial and full participation, which are seen as processes in which two or more parties influence each other and final decision is made by one party only in partial or by everyone together in full participation (Pateman, 1976), and points out that beside "granting access" and "facilitating interaction", the participatory process is also about "balanced power relations and co-decision making" (Carpentier, 2007).

According to Witschge (2007), the Internet represents "a new discursive space", where every person can present their own view. This could lead to more inclusion and participation in the public debate for everyone and not only political elites. That is possible especially because the Internet is characterized by many-to-many communication or many-to-one (in opposition with the classical forms of media with one-to-many or one-to-one form communication) and because the online campaigns are based on interaction which should reduce citizens' apathy and increase the participation (Chadwick, 2006). In that sense, Lusoli et al. also mention the Internet potential to attract citizens and widen the participation, under the condition that citizens receive a response that "their participation and communication is valued and listened" (Lusoli et 
al., 2006: 40). Street and Wright stress the importance of discussion in which citizens are engaged, which appears possible through the Internet and online discussion forums (Street \& Wright, 2007).

When discussing the participation on Facebook, the first issue is how people engage in this SNS space. In regards to that, we have come to the following conclusion. There should be a distinction made between 3 different levels: the first level, when one becomes a "friend" with a certain political actor or an institution like the EP, the second level when one puts "like" on other people's comments and the third level when one comments on other people postings. The third level - citizens putting comments, can be seen as a sort of political engagement, while that can be hardly said for the other two levels. This distinction is important especially for further analysis of a political profile page because different levels of participation should be clearly separated and distinguished.

\section{Social Network Sites}

The concept of a social network is not a new one $e^{5}$. It has usually been related to the notion of interpersonal communication and identity theory, as identities emerge from social interaction with others (Dalsgaard, 2008). Web 2.0 environment includes social network sites, the notion that grew from the term "social network" used in social sciences in the "offline" surroundings, which was then merged with the technical meaning of the word "network" (for an SNS definition see e.g. Gane \& Beer, 2008; boyd \& Ellison, 2008).

SNSs create a new way of how people are organized, in the so-called "network society", (Castells, 2008). "So it's not just about networks or social networks, because social networks have been very old forms of social organization. It's about social networks which process and manage information and are using micro-electronic based technologies" (Kreisler, 2001). For Castells, networks are "open structures", representative of decentralized and flexible society, made of individuals (Gane \& Beer, 2008: 20). Facebook offers useful space for supranational political organizations like the European Parliament first because it is flexible, which makes it different from other media (Bimber et al., 2008), because it can reach more audience than classical media (as there is no traditional media published/broadcasted on the EU level). At the same time, social network sites are suitable for communication about political issues because young adults use them often, therefore through entertaining and informing the

5 The English anthropologist Elizabeth Bott wrote about social networks of London families back in 1957 in her book "Family and social networks". 
audience, they can get a feeling of being closer, which could encourage them to engage in politics.

Just like in any offline social network, human connections are created between the nodes (that create an online network). These ties can be week, strong or intermediate, but a difference between offline and online social networks is that, as there is an online interaction between the participants, the network can be (and usually is) easily expanded by establishing the connections between people who do not actually know each other (for example, based on mutual professional affiliation or personal interests).

According to the study led by compete.com in January 2009, facebook. com, a global SNS founded in 2004, was ranked the first as the most used social network site by the number of active users each month (Kazeniac, 2009) and according to the same website data from September 2009, it has $150 \%$ more visitors compared to MySpace, its biggest competitor (Monthly Normalized Metrics, 2009), with 124,579,479 active users during the month of September 2009. Facebook provides many interactive tools for users, such as writing on the "wall" (empty space on every profile where other users, "friends" can post messages that all the other "friends" can see and read), "status" that all users can write on their own profile so that their "friends" can read it and comment on it, pictures, with the possibility to upload pictures and tag people who are on them, write comments beneath, etc. That is the reason why it got an important role in political communication nowadays. Many politicians have profiles on Facebook and in April 2009, the European Parliament started its campaign for widening participation on the elections there, by creating its own "profile", which made it, according to Stephen Clark, Head of Web Communication Unit, Directorate General for Communication, European Parliament, the first political institution on a social network website in Europe and maybe larger (personal communication, June 10, 2009). It is important to grasp the term "fan" on Facebook and what it means to be a fan of a certain politician, and then to discover what Facebook can actually do and change in political communication.

The use of SNSs in political campaigns has been relatively understudied, especially in Europe, as it is a relatively new phenomenon that increased the massive (and successful) use of Facebook during the U.S. campaign $2008^{6}$. Some scholars, when discussing campaigning on Facebook, refers to them as

\footnotetext{
${ }^{6}$ Albeit the first major use of an SNS in political communication was done by Dean on MeetUp, which provided "an undeniable demonstration of the new medium's political power" (Hindman, 2005: 127) and Kerry on Friendster, in 2004.
} 
"soft" campaigns because they are similar to the appearance of politicians in some entertainment shows, with the difference of having more interactivity on Facebook (Utz, 2009).

Based on that, some of the issues that we want to raise in this paper are what kind of messages are posted to attract younger audiences, what the principle of integration of political/institutional communication into social network sites is and whether Facebook act as a mobilizing tool or as a supporters' informing tool only. That leads us to the first research question.

RQ1: What was the mobilization campaign strategy of the European Parliament on Facebook?

Along with the European Parliament strategy, one of the main features on Facebook is the participation of the audience (in the meaning of SNS users), and that is especially important because the majority of participants on Facebook use their real names (and even pictures), so that they are not just anonymous participants as elsewhere (e.g. on YouTube, participants in the discussion never use their real names, but "user names", that is pseudonyms). Therefore, it would be significant to explore the role of the public that is actually posting on the European Parliament's profile. This will be formulated in the second research question.

RQ2: What kind of participation and interaction is present on the page of European Parliament's Facebook profile?

\section{Data collection and methods}

We gathered posts and answers, placed on the European Parliament's Facebook profile during a period of two weeks, between May 20, 2009 (one month after the start of using facebook.com application) and June 3, 2009 (last day before the official start of the elections), i.e., during the last two weeks of the campaign for widening participation of EU citizens. This period should be the peak of the campaign because it represents the last 14 days before the elections.

Based on the Grounded Theory (Glaser \& Strauss, 1967), coding categories were chosen inductively. For the analysis, we have used Computer-Mediated Discourse Analysis (CMDA). CMDA is used for studying the online discourse behavior of participants in the discussions, their interactions, in-group language, speech acts; thus its focus is on the language and its use (Herring, 2001). CMDA basic methodological orientation is qualitative and quantitative content analysis, but it extends its traditional meaning (Herring, 2004). 
Therefore, the content analysis becomes web content analysis, which represents the application of content analysis techniques to web content or analysis of web content using different techniques (Herring, 2009). CMDA is used especially for analyzing the participation and the "phenomena of interest are number of messages and responses and message and tread length" (Herring, 2004: 358). As the unit of analysis, we have used the format of one post (i.e., comment) ${ }^{7}$, whether it was posted by the European Parliament itself or by one of the participants in the discussion (Kushin \& Kitchener, 2009).

\section{Results and discussion}

When the data were collected (June 2009), the European Parliament's profile had reached approximately 50,000 fans. After the initial quantitative analysis of the text that gave us a general overview of the material, we got the following results. During the two analyzed weeks, the European Parliament posted textual-audio-visual material 16 times (slightly more than one post per day) and received 966 feedback posts (67 posts per day), out of which 767 "likes" (40.4 "likes"/post) and 229 comments (approximately 12 comments/post).

Comments only (without "likes") were written by 165 different persons, which represents only $0.3 \%$ of the total number of fans. Out of those 165 persons, it is interesting to notice that 105 persons that posted comments were males (63.6\%) and 60 females (36.4\%), which corresponds with the ratio of female representation in the European Parliament (35\%) albeit the sex ratio in the European Union is different: $48 \%$ males / 52\% females (and the ratio of Facebook users is 45\% / 55\%, albeit the data is for the USA only (Quantcast, 2010). This could mean that male participants were more interested in participating in the discussion, but also that they are in general more interested in politics, at least among young adults. This can be crosschecked by comparing the Eurobarometer survey, i.e., the interest citizens have shown for the elections: $51 \%$ of males responded that they are interested, compared to $44 \%$ of females (Eurobarometer, 2008), but it can be seen as a trend that continues in the "online" world. Unfortunately, there are no data about the sex ratio when it comes to participation in the offline campaign activities.

Also, it should be mentioned that the comments were written in 12 different languages (11 European and 1 non-European) out of which $81.9 \%$ were written in English, followed by Spanish (5.4\%) and French (3.6\%). The use of

\footnotetext{
The names are replaced with initials for privacy reasons.
} 
language is explained in more detail in the further qualitative analysis of comments.

It is common for social networks and fan pages that participants join the group/fan pages with a similar opinion to their own (Kushin, Kitchener, 2009) and the European Parliament profile follows that principle $56.7 \%$ of comments are positive ${ }^{8}, 10 \%$ negative and $33.3 \%$ neither positive nor negative, as they are usually considering language use, which will be shown later), albeit different opinions would lead to a more productive discussion and opinion exchange. This can also be explained through collective action, when the individuals involved in the group are rather homogenous (Marwell et al., 1988).

In addition, the European Parliament itself responded twice to the discussion that was developed, which can be seen as an example of two-sided communication and shows that the comments are actually read by the European Parliament, i.e., people in charge of the European Parliament communication. This can be used as an argument for two-sided communication, where one side reads and replies to what the other writes and vice versa.

The qualitative analysis was used for further analysis of posts and comments, because it can provide greater detail. The analysis of the discourse must be divided in:

1. The analysis of the EP posts,

2. The analysis of comments.

\section{The EP Posts}

The European Parliament posts can be grouped in four clusters according to their topic and message:

1. Persuasive posts or posts inviting citizens to vote (3 posts);

2. Explicative posts or posts explaining how to vote or who to vote for (3 posts);

3. Entertaining posts, posts suggesting the use of gadgets (fun/game tools) (4 posts);

4. Informative posts, more informative posts about the results of opinion polls, things that the European Parliament did or is planning to do and how it works (6 posts).

\footnotetext{
${ }^{8}$ Comments qualified as positive are either positive in relation to the European Parliament as a holder of a profile page or positive in relation to the post written by the European Parliament and vice versa. The third category of "neither positive, nor negative" are comments that are not an answer to the topic posted beneath.
} 
From these four clusters, it is clear that the EP has tried to provide at the same time a mobilizing (through persuasive and entertainment posts) and supporters' informing (through explicative and informative posts) tool.

Albeit the entertainment has become a part of every political campaign (Street, 2003), as its element helps in creating affective ties with the electorate, the entertaining posts on Facebook have had a slightly different role. With its content (funny widgets), they have directly revealed that their target group are young adults. That is common for an SNS campaign, especially if the demographic data are taken into consideration: 66\% of Facebook users are between 18 and 34 years (although the data concerns only the USA territory, as there is no statistics for the Facebook users from the EU) (Smith, 2009).

The themes are not separated by time, rather they are mixed. The informative posts are more present during the first week of observation. In the middle of this period, there are some entertaining posts that present the use of funny widgets (YaBs ${ }^{9}$, badges, Choice boxes) and explicative posts that explain where to find the information about who is running and how to vote. The last two days before the start of the elections were dedicated to more general, informative posts about how to vote, they gave results of the opinion poll which is in favor of the European Parliament and provided links for two videos with celebrities who are explicitly telling the target audience that they will vote and, implicitly, that everybody should do the same, which makes them persuasive by the approach they use. These four clusters are in compliance with any (political) marketing campaign that consists of information and entertainment for voters/ consumers, which leads to persuasion. They also reveal the campaign rhythm on a time axis, starting with more general, informative posts, continuing with entertaining and explicative posts and finishing with persuasive ones. Like other posts on Facebook, when it comes to size, the European Parliament posts are short (no more than 50 words) and usually consist of one to five (if five, then very short) sentences of introduction to the topic and explanation and then a "read more" syntagm with a link, where the larger information can be found in the form of a text, a video or an application. Therefore, it can be said that the campaign strategy by the structure of postings is adjusted to the medium that is used, in this case Facebook.

\footnotetext{
9 YaBs were 27 toys produced by the European Parliament and distributed to people from different EU states (each $\mathrm{YaB}$ was given to a person from a different state) with the goal to reach one chosen celebrity in that particular country in given time, using the notion of "six degrees of separation" or "human web".
} 
All posts are directly addressed to the public: if we make a distinction according to the sentence function, six posts are interrogative, e.g. explicative posts: "Have you decided yet on how to vote in the EU elections?" (June 3, 2009), "Want to check who's running to become an MEP and wants your vote?" (May 29, 2009), entertaining posts: "Who will be the next YaB super star?" (June 2, 2009); while five are exclamative or imperative, e.g. persuasive posts: "Vote wherever you are" (June 3, 2009), "Show your intention to participate" (May 24, 2009), type 3: "Create a badge here" (May 30, 2009), "Send your video message" (May 20, 2009); and the others are declarative, e.g. informative posts: "Thursday morning polling stations will be open in the Netherlands and the UK" (June 2, 2009), "5 things the European Parliament did in the past five years" (May 29, 2009). From this analysis, it is obvious that persuasive posts are rather imperative or exclamative, explicative posts are interrogative, entertaining posts are both interrogative and exclamative and informative posts are mostly declarative. Like in every commercial or political campaign, all posts, especially those written in the imperative and interrogative mode, try in a more or less explicit way to motivate their readers to participate in the elections, e.g. "European Parliament elections are about choices for future policies" (May 30, 2009), "5 things the European Parliament did [...] and five things you can do in the next five years" (May 29, 2009), "[...] you can find out how your personal beliefs and opinions match with the candidates and political parties" (May 28, 2009), "Recent opinion poll indicates growing interest of EU citizens" (May 27, 2009).

The construction of sentences written on the profile is similar to the construction of political slogans: they need to be short, explicative and they need to call for an action.

Besides, every post has a full-color picture or a video under it, as a kind of additional information, that brings positivity and colorfulness, but it also has a persuasive role. This leads to the conclusion that the profile page is, when it comes to posts themselves, well designed.

Another noticeable lexical remark concerns the use of the second person of singular/plural in almost every post: either as a personal pronoun "you" or a possessive pronoun "your". That also shows the intention of the European Parliament to speak directly to voters and to create a sort of direct link with them, but it is also linked with giving orders to the others, especially when exclamative sentences are used. 
At the very end of the campaign, the last two days before the elections, the European Parliament posted two very interesting posts that are, as expected, type 1 posts. The first post claims that European sports stars call on citizens to participate in the elections, with a link originally posted on EuroparlTV (the official European Parliament TV channel). The second repeats the words of an astronaut, who is currently on a space station, "Vote wherever you are", with a link to the video posted on youtube.com. This post had the highest number of "likes" and comments, 157 in total. These posts and also videos are typical political campaign spots in which celebrities give their support to an idea or a party/candidate in order to attract citizens. In fact, they represent the last minute strategy, popular in the political marketing.

From this analysis, we have received the answer to the first research question about the EP campaign strategy on Facebook. We have shown how a classical political campaign needs to be adjusted to a new medium, in this case a social network site, both by the regularity of posting as well as by the structure itself. Although the form has changed, the rhetoric in its essence has remained the same. This gives us the opportunity to think about this sort of political campaigning and its wider significance, in the context of political communication, although it is impossible to measure its effects.

\section{Comments of online audiences}

In analyzing comments, the first element to be discussed are the "likes" after every post. They are a new Facebook invention and are used to illustrate liking an idea. They can be seen as a sort of partial interaction. We can assume several things: that those people really like the text of the post (the idea), that they like the text or video linked to it or that they just like the general approach of the European Parliament. We will consider it as an agreement with the entire text/article/video (the post and the link). Unfortunately these "likes" cannot be analyzed qualitatively, yet they can be counted. There were approximately 40 "likes" per post, which is in conformity with the general idea of joining a group if one has a similar opinion, but to a certain extent it also represents the support that the citizens give to the European Parliament and this way of leading a campaign.

When it comes to comments, the majority of them are very short, laconic, in just a word or two, e.g. "good message, bad editing" (M.O., June 3, 2009), "inspiring and somehow touching $\odot$ ") (S.D., June 3, 2009), "me like" (K.B., 
June 3, 2009), "good job!" (R.W., May 29, 2009), "great @)” (J.P., May, 24 2009), "thats sooo cool :D” (E.M.G., May 24, 2009).

That is a characteristic of posting on the social network sites and above all among youngsters in general. Out of 219 comments, just a few of them are larger, explaining their perspectives in more details.

There is a group of comments posted by people who want to see different information in different languages. Taking into consideration that language is a part of identity construction (Gibson, 2004), it can be considered as the multiculturalism of the European Union and a part of the European identity, but also as a part of their national identity. Some of them insist on the European Parliament to start posting in other EU languages, e.g. "en espagnol" (V.M.S. May 29, 2009), "en français" (V.D. May 29, 2009), "en catala” (J.-E.P., May 29, 2009), "suomeks!! In finnish" (O.S., May 29, 2009), with the arguments that there are 27 official EU languages and not just English, albeit according to Wodak and Wright (2006), in online discussions, English can be considered as a "lingua franca" of the European Union. Along with that, there are also some comments, especially in the last days before the elections that accent both the national and the European identity, e.g. "proud to be Belgian and European :c)))" (T.W., June 3, 2009), "proud to be Irish and European" (C.M., June 3, 2009).

Like in every discussion group on the Internet, there seems to be some irrelevant posts for the topic, not linked with the European Parliament profile and posts, some of them with links to videos on youtube.com that do not deal with any of the relevant subjects. This is a way to promote certain ideas between gathered people, especially if a group has a high number of fans.

Some comments mention who to vote (or who not to vote) for in different countries, e.g. "help us from Berlusconi. Please Europe!!!” (G.R., May 27, 2009) or "piratpartiet!" (H.P., June 3, 2009), and they are written with the evident aspiration to influence other voters from the same country.

Many comments are written using smiley faces, graphic icons built of punctuation marks which represent different emotions and use the computerized colloquial contractions in English language spelling, which implies that the authors are young people, e.g. :-) , :-D, "thats" instead of "that's", "u" instead of "you" etc. There are also several comments from people who are not EU citizens or EU residents.

We considered as core participants, in those two examined weeks, people who posted four or more times. There are six such participants: three of them 
posted 4 times, one posted 5 times, one posted 6 times and one posted 9 times. D.S. who posted 4 times is concerned with the national politics in his home country, he mentions his national identity, explicitly says for whom he will not vote and gives his view on national politics and voters in his country. He posted in the last days before the elections. D.C.C. also posted 4 times, with two posts written in his mother tongue with which he accents his national identity, too. His opinion is slightly unclear. F.F. also posted 4 times during this period and he is very much in favor of the European Parliament and his ideas, so that he even offends other participants in the discussion by defending the European Parliament views. K.D. posted 5 times and she completely opposes the European Parliament views, albeit she is in favor of the idea of a European Union and European Parliament as such. T.A. posted 6 times, out of which 5 times he gave only links to another group on Facebook that could not be opened, but we can assume that it was irrelevant for the topic, as was also the case with the sixth post. R.B. posted 9 times, his opinion is interesting, he openly discusses his position and albeit he is likely to participate in the elections (and he is in favor of compulsory voting), he criticizes many political parties and MEPs. This analysis shows us that, albeit the majority of comments are in favor of the European Parliament and elections, six core participants have quite different views and opinions, which develops the communication between them, as long as there are no direct offenses, which are sanctioned by deleting them from the web page (S.Clark, personal communication, June 10, 2009).

This analysis has shown the manner of participation and interaction of online audiences, active on the EP profile page on Facebook. We have seen that only $0.3 \%$ of EP fans were actively involved in the discussion, but we have also observed the way they participate: by putting only "likes", writing short comments, using colloquial contractions and revealing their national/EU identity by choosing the language in which comments were written or explicitly with words. This can be translated on a more general level, as a characteristic of the majority of comments on Facebook.

\section{Conclusion}

Castells (2008) suggests that new information and communication technologies allow the connection of everything and everyone in the world. Many scholars nowadays argue that the Internet can be used as a mean to widen the citizens' participation (e.g. Dahlgren, 2004; Chadwick, 2006; Gane \& Beer, 2008). The European Parliament created the 2009 campaign according to these 
recommendations, by introducing new features on the website and also by participating in several social network sites.

The main goal of this paper was to analyze the way Facebook was used during the European Parliament campaign and, to a certain extent, show the possibilities of using social network websites in political communication in Europe. In order to respond to two research questions, the results' section was divided in two parts, the first part dealing with the campaign strategy of the European Parliament on Facebook and the second part that included the analysis of participants' discussions on the European Parliament's profile page.

We have examined only the last two weeks before the elections and based on this, we have shown political marketing strategies and techniques that the European Parliament used for its campaign in order to widen the participation in the elections. Its Facebook campaign was aimed at a younger audience as $67 \%$ of the Parliament's Facebook "fans" are under 35 years old. It was well structured and intensified in the last couple of days. We also noticed that it was quite successful, taking into consideration that the profile was created in April and since then it has had 51,000 fans, with 52.4 answers per European Parliament post. For some, this number may seem not large enough when taking into account the entire EU population, but according to the critical mass model, there is always a small number of individuals interested in collective action. The topics posted were relevant (comparing to the topics published in other online and offline media) and they were in conformity with the established frame of posts on Facebook (concise, summarizing and attractive).

On the other side, we can assume that the EU citizens missed stronger connection with the European Parliament (Wodak \& Wright, 2006) and that this could be considered a good move of the European Parliament in terms of getting closer to citizens, especially to a younger audience, and more open. Citizens obviously found the idea of having the European Parliament's profile on Facebook interesting and that is the reason why so many of them almost instantly became "fans" of the European Parliament. In this way, citizens got an opportunity to be engaged in the political debate, which they had promptly started to use. It can be noticed furthermore that the nonymous online environment such as Facebook, where the majority of users use their real names and pictures and accentuate their national, EU and/or political identity, had positive impact on the discussion, keeping it more linked to the topic than on other social network sites where the participants are anonymous. When analyzing their online identities, we found out that the online audiences identified 
themselves both with their national and European identity (which is not in compliance with the Eurobarometer survey, but we can assume that EP "fans" are stronger identified with the EU and EU institutions than other citizens) and to stress their identities explicitly (which is in opposition with the view of Zhao et al. (Zhao et al., 2008) that Facebook users mostly show their identities implicitly). We analyzed opinions of individuals from different countries, speaking different languages, with diverse political views, who wanted to participate in or abstain from the elections. The majority of comments were very relevant to the discussion about the elections. These results explain the purpose of the study, to reveal campaign strategy of a political institution made for a web 2.0 application but at the same time different levels of (political) participation on Facebook among European audiences.

Albeit he admits that politics will never be as popular as entertainment or commerce on the Internet, Klotz (2004) argues that "the Internet is providing an additional medium through which individuals can pursue the privileges and obligations of citizenship" and that it is used by citizens in order to "receive information, mobilize and interact with the government" (Klotz, 2004: 42).

Despite on-going doubt about how much the European citizens are interested in participating in political communication, this study revealed their willingness to take part in the decision-making processes and political communication. That means that the possibility for using SNSs in political communication on the European grounds exists, it is only a question whether and how it has been and will be used by political actors and institutions.

\section{Limitations}

It should be noted that the study is limited to an online campaign on an SNS, and it consists of two weeks prior to the elections (as a peak of the campaign). For a greater generalization, a longer period of time should be taken into account. Also, it would be interesting to further compare between online and offline campaign communication, and the use of SNSs with press releases, speeches etc. 


\section{References}

Baumgartner, J. \& Morris, J. (2010). MyFace tube politics: Social networking web sites and political engagement of young adults. Social Science Computer Review, 28(1): 24-44.

Bimber, B., Stohl, C., Flanagin, A. (2008). Technological change and the shifting nature of political organization. In Chadwick, A. \& Howard, P. N., Routledge handbook of Internet politics. New York: Routledge, pp. 72-85.

boyd, d., Ellison, N. (2008). Social network sites: Definition, history, and scholarship. Journal of Computer-Mediated Communication, 13: 201-230.

Carpentier, N. (2007). Participation, access and interaction: Changing perspectives. In V. Nightingale \& T. Dwyer. New Media Worlds. Challenges for Convergence. OUP Australia \& New Zealand, pp. 214-228.

Castells, M. (2008). The new public sphere: Global civil society, communication networks and global governance. ANNALS, AAPSS, 616.

Chadwick, A. (2006). Internet politics: States, citizens and new communication technologies. New York: Oxford University Press.

Dahlgren, P. (2004). Foreword. In Van de Donk, W., Loader, B., Nixon, P. \& Rucht, D., Cyberprotest, New media, citizens and social movements. London, New York: Routledge. XIXVI.

Delli Carpini, M. D. (2000). Gen.com: Youth, civic engagement, and the new information environment. Political Communication, 17: 341-349.

Eurobarometer (2008). Eurobarometer 68. Public opinion in the European Union. Accessed 18. 10. 2009. URL: http://ec.europa.eu/public_opinion/ archives/eb/eb68/eb_68_en.pdf.

European Parliament (2009a). European elections. Accessed 03. 03. 2009. URL: http://www.europarl.europa.eu/elections2009/default.htm?language=en.

European Parliament (2009b). Turnout at the European Elections. Accessed 12. 10. 2009. URL: http://www.europarl.europa.eu/parliament/archive/elections2009/en/turnout_en. html.

European Parliament, 2009 elections (2009c). What impact will sites like Facebook and YouTube have in the EP elections? Accessed 20. 02. 2009. URL: http://www.europarl.europa.eu/elections2009/welcome/headlines.htm?lang uage $=E N \&$ ref $=20090205$ STO48542\&secondRef $=0$.

Facebook (2010). Statistics. Accessed 16. 10. 2010. URL: http://www.facebook. com/press/info.php?statistics.

Gane, N. \& Beer, D. (2008). New media. Oxford: Berg Publishers. 
Gibson, K. (2004). English only court cases involving the U.S. workplace: The myths of language use and the homogenization of bilingual workers' identities. Accessed 21. 10. 2009. URL: http://www.hawaii.edu/sls/?link=working_papers.

Glaser, B. \& Strauss, A. (1967). The discovery of grounded theory: Strategies for qualitative research. Chicago: Aldine.

Herring, S. C. (2001). Computer-mediated discourse. In D. Schiffrin, D. Tannen \& H. Hamilton (eds.), The handbook of discourse analysis. Oxford: Blackwell Publishers, pp. 612-634.

Herring, S. (2004). Computer-mediated discourse analysis: An approach to researching online behaviour. In S. A. Barab, R. Kling \& J. H. Gray (eds.), Designing for virtual communities in the service of learning. New York: Cambridge University Press, pp. 338-376.

Herring, S. (2004). Content analysis for new media: Rethinking the paradigm. In New research for new media: Innovative research methodologies symposium working papers and readings. Minneapolis, MN: University of Minnesota School of Journalism and Mass Communication, pp. 47-66.

Herring, S. (2009). Web content analysis: Expanding the paradigm. In J. Hunsinger, M. Allen \& L. Klastrup (eds.), The international handbook of Internet research. Berlin: Springer Verlag.

Hindman, M. (2005). The real lessons of Howard Dean: Reflections on the first digital campaign. Perspectives on Politics, 3(1): 121-128.

Kazeniac, A. (2009). Social networks. Facebook takes over top spot, twitter climbs. Accessed 14. 10. 2009. URL: http://blog.compete.com/2009/02/09/facebook-myspace-twittersocial-network/.

Klotz, R. (2004). The politics of Internet communication. Lanham: Rowman and Littlefield.

Kreisler, H. (2001). Identity and change in the network society. Conversation with Manuel Castells. Conversations with History. Institute of International Studies, UC Berkeley.

Kushin, M. \& Kitchener, K. (2009). Getting political on Social Network Sites: Exploring online political discourse on Facebook. The annual convention of the Western States Communication Association, Phoenix.

Lusoli, W. (2005). The Internet and the European Parliament elections: Theoretical perspectives, empirical investigations and proposals for research. Information Polity, 10: 153-163. 
Lusoli, W., Ward, S. \& Gibson, R. (2006). (Re)connecting politics? Parliament, the public and the Internet. Parliamentary Affairs, 59(1): 24-42.

Maarek, P. \& Wolfsfeld, G. (2003). Political communication in a New-Era: A cross-national perspective. London: Routledge.

Marwell, G., Oliver, P. \& Prahl, R. (1988). Social networks and collective action: A theory of the critical mass. III. The American Journal of Sociology, 94 (3): 502-534.

Marwell, G., Oliver, P. (1993). The critical mass in collective action: A microsocial theory. London: Cambridge University Press.

Monthly Normalized Metrics (2009). September 2009. Accessed 14. 10. 2009. URL: http://siteanalytics.compete.com/facebook.com+myspace. com+twitter.com/.

Mouffe, C. (1999). Deliberative democracy or agonistic pluralism. Social Research, 66 (3): 745-758.

Noelle-Neumann, E. (1984). The spiral of silence: Public opinion - our social skin. Chicago: University of Chicago Press.

Norris, P. (2004). The bridging and bonding role of online communities. In P. Howard \& S. Jones, Society online: The Internet in context. Thousand Oakes: Sage Publications, pp. 32-43.

Oliver, P., Marwell, G. \& Texteira, R. (1985). A theory of the critical mass. I. Interdependence, group heterogeneity, and the production of collective action. The American Journal of Sociology, 91 (3): 522-556.

Pateman, C. (1976). Participation and democratic theory. Cambridge: Cambridge University Press.

Quantcast. Facebook.com. Accessed 12. 04. 2010. URL: www.quantcast.com/ facebook.com.

Smith, J. (2009). Fastest growing demographics on Facebook: Women over 55. Accessed 12. 04. 2010. URL: http://www.insidefacebook.com/2009/02/02/ fastest-growingdemographic-on-facebook-women-over-55/.

Street, S. \& Wright, J. (2007). Democracy, deliberation and design: The case of online discussion forum. New Media Society, 9 (5): 849-869.

Utz, S. (2009). The (potential) benefits of campaigning via Social Network Sites. Journal of Computer-Mediated Communication, 14: 221-243.

Valente, T. (1996). Social network thresholds in the diffusion of innovations. Social Networks, 18: 69-89.

Webopedia (2010). Facebook Like. Retrieved March 14, 2010, from http:// www.webopedia.com/TERM/F/Facebook_Like.html. 
Witschge, T. (2007). Representation and inclusion in the online debate: The issue of honor killings. In B. Cammaerts \& N. Carpentier (eds.). Reclaming the media: Communication rights and democratic media roles. Bristol: Intellect books, pp. 130-156.

Wodak, R. \& Wright, S. (2006). The European Union in cyber-space: Multilingual democratic participation in a virtual public sphere? Journal of Language and Politics 5(2): 251-275.

Zhao, S., Grasmuck S. \& Martin, J. (2008). Identity construction on Facebook: Digital empowerment in anchored relationships. Computers in $\mathrm{Hu}$ man Behavior 24: 1816-1836. 